\title{
Final results of the multicenter, prospective Axium MicroFX for Endovascular Repair of IntraCranial Aneurysm Study (AMERICA)
}

\author{
Kyle M Fargen, ${ }^{1}$ Spiros Blackburn, ${ }^{1}$ Eric M Deshaies, ${ }^{2}$ Jeffrey S Carpenter, ${ }^{3}$ \\ Pascal Jabbour, ${ }^{4}$ William J Mack, ${ }^{5}$ Ansaar T Rai, ${ }^{3}$ Adnan H Siddiqui, ${ }^{6}$ \\ Raymond D Turner, ${ }^{7} \mathrm{~J} \mathrm{Mocco}^{8}$
}

For numbered affiliations see end of article.

\section{Correspondence to Dr Kyle M Fargen, Department of Neurosurgery, University of Florida, Gainesville, Box 100265, Gainesville, FL 32610, USA; kyle.fargen@neurosurgery.ufl. edu}

Received 23 November 2013 Accepted 15 December 2013 Published Online First

6 January 2014

\section{CrossMark}

To cite: Fargen KM,

Blackburn S, Deshaies EM,

et al. I Neurolntervent Surg 2015;7:40-43.

\section{ABSTRACT \\ Background We previously performed a multicenter prospective single-arm trial of 100 patients treated with Axium MicroFX Coils (ev3; Plymouth, Minnesota, USA), AMERICA: Axium MicroFX for Endovascular Repair of IntraCranial Aneurysm study. Initial angiographic and clinical outcomes were excellent. The final results are presented herein.}

Methods AMERICA is a multicenter, prospective single-arm trial evaluating the safety and efficacy of the ev3 Axium MicroFX coil system in 100 separate aneurysms between April 2010 and October 2012. Trial endpoints were 3-6 month angiographic occlusion and clinical status, as reported by treatment center.

Results Mean follow-up was 157.9 days (median 153.5, range 1-445, SEM 9.3 days). At last follow-up imaging, $90.6 \%$ of all aneurysms, $90 \%$ of unruptured aneurysms, and $93.3 \%$ of ruptured aneurysms had Raymond grade I or II occlusion. Progression to further occlusion (lower Raymond occlusion grade) occurred in 29/85 aneurysms (34.1\%). Aneurysm recurrence occurred in 11/85 aneurysms (12.9\%). Ninety-nine per cent of patients treated electively and $68.7 \%$ of ruptured patients had a modified Rankin score of $0-2$. Delayed adverse events (AEs), occurring after discharge and during the follow-up period, occurred in $10 \%$ of patients. In total, two AEs (one severe and one moderate) were potentially related to the device, thereby providing a $2 \%$ device-related $\mathrm{AE}$ rate.

Conclusions In this prospective, multicenter series of 100 aneurysms treated with Axium MicroFX PGLA (polyglycolic/polylactic acid) coils, 3-6 month angiographic occlusion and clinical outcomes were excellent. This study suggests that Axium MicroFX PGLA coils are safe and effective in the treatment of intracranial aneurysms.

\section{INTRODUCTION}

Polyglycolic/polylactic acid (PGLA) coils are coated with bioactive microfilaments aimed at promoting aneurysm thrombosis after endovascular coil embolization. Axium MicroFX Coils (ev3; Plymouth, Minnesota, USA) contain PGLA microfilaments designed to significantly affect intra-aneurysmal flow and to encourage aneurysm thrombosis. To evaluate the safety and efficacy of the MicroFX design, we performed a multicenter prospective single-arm trial of 100 patients, AMERICA: Axium
MicroFX for Endovascular Repair of IntraCranial Aneurysm study. We previously presented our shortterm results, ${ }^{1}$ in which $83 \%$ of the 78 electively treated patients had Raymond grade I or II occlusion and $94 \%$ had a modified Rankin score (mRS) of 0 2 at time of discharge. In addition, $91 \%$ of the 22 patients with ruptured aneurysms had Raymond grade I or II occlusion and $62 \%$ had a mRS of $0-2$ at discharge. Device-related complications occurred in only $2 \%$ of patients. The final results, including clinical and angiographic outcomes at 3-6 months after the procedure, have recently been completed and are presented herein.

\section{METHODS}

AMERICA is a multicenter, prospective single-arm trial evaluating the safety and efficacy of the ev3 Axium MicroFX coil system. Detailed methodology has been presented previously. ${ }^{1}$ The trial was designed to include 100 separate aneurysms treated with Axium coils. Enrollment was initiated in April 2010 and completed in October 2012. The primary endpoint of the trial was the anatomic occlusion of the aneurysm in the immediate post-procedure angiogram based on the Raymond classification. ${ }^{2}$ Secondary endpoints included safety during the procedure, defined as the rate of morbidity and mortality evaluated at hospital discharge; safety after the procedure, defined as the morbidity and mortality at 3-6 months after the procedure; detachment system performance, defined as the occurrence of detachment failure during the coiling procedure; stability of embolization, defined by the rate of change towards worsening Raymond grades over the follow-up period; and packing efficacy, defined as the increase of packing density calculated as the ratio of the volume of coils and the aneurysm volume, at 3-6 months after the procedure. All enrolled patients underwent coiling between April 2010 and October 2012, and scheduled follow-up clinical visits and angiographic imaging at 3-6 months' follow-up were planned. The evaluation was considered complete once patients had undergone their 3-6 month imaging and clinical follow-up; a small number of patients were followed up beyond 1 year but not within 6 months. In these patients, the last available follow-up was used as a surrogate for their 3-6 month follow-up data. Raymond occlusion 
grades and clinical outcome status were determined and reported by each treatment center.

Inclusion and exclusion criteria have been previously reported. ${ }^{1}$ All aneurysms that met the inclusion criteria and did not meet the exclusion criteria were treated with a target of at least 90\% Axium MicroFX PGLA detachable coils; however, all enrolled patients were followed up regardless of the achieved percentage of Axium coils used. Use of coil assist devices (eg, stents, balloons, etc) was allowed and recorded. The data collected were analyzed in an intention-to-treat manner.

An adverse event (AE) was defined as any undesirable clinical occurrence in a patient whether it was considered to be device related or not. This definition includes events occurring during the enrollment in the study right up to the last follow-up visit. All AEs reported were given a severity rating of mild, moderate or severe by the treatment center. Mild AEs were defined as an event in which the patient is aware of signs or symptoms, but easily tolerates them; of minor irritant type; causing no loss of time from normal activities; do not require medication or a medical evaluation; are transient; and/or resolve during the procedure. Moderate AEs were defined as discomfort severe enough to cause interference with, or reduce, usual activities; persist after the procedure or require treatment, but do not require hospitalization or intensive care for the patient. Severe AEs were defined as those with significant impairment of functioning; patient is unable to carry out usual activities. A device malfunction was defined as any case in which a device used during the procedure does not perform as intended when used in accordance with the 'instructions for use'.

\section{RESULTS}

\section{Patient characteristics and procedure}

Ninety-nine patients underwent treatment with PGLA coils for 100 cerebral aneurysms at 13 study centers between April 2010 and October 2012. Patient characteristics at presentation, aneurysm location, and procedural nuances have been reviewed in detail previously. ${ }^{1}$ In brief, the mean age of the patients was 60.2 years (range 18-89 years, SEM 1.3), most patients were female $(72 \%)$, $18 \%$ of enrolled patients had previously undergone treatment for a separate aneurysm, and $22 \%$ of patients underwent treatment after acute aneurysmal subarachnoid hemorrhage (SAH). Of these patients, all were Hunt and Hess grade $1-3$. The majority of aneurysms were anterior circulation $(86 \%)$, with the most common aneurysm locations being the anterior communicating artery $(23 \%)$, followed by both the posterior communicating artery and supraclinoid artery $(18 \%$ each). The mean maximum aneurysm diameter was $6.5 \mathrm{~mm}$ (median $6.1 \mathrm{~mm}$, range $2.5-12.6 \mathrm{~mm}$, SEM 0.2). The mean neck size was $3.4 \mathrm{~mm}$ (median $3.1 \mathrm{~mm}$, range $1.5-10 \mathrm{~mm}$, SEM 0.5 ). The average neck:dome ratio was 2.0 (range 1-3.9, SEM 0.1 ). Forty-eight per cent of patients underwent primary coiling,
17\% underwent balloon-assisted coiling, 32\% underwent stent-assisted coiling, two patients were treated with both balloon and stent assistance, and one patient underwent treatment with adjunctive liquid embolic agent. Axium coils were placed in all but one procedure (99\%).

\section{Follow-up}

Of the 100 aneurysms that underwent coiling, 85\% had angiographic follow-up occlusion data and $89 \%$ had clinical outcome status reported. Mean follow-up was 157.9 days (median 153.5, range $1-445$, SEM 9.3 days), or about 5.2 months.

\section{Angiographic results}

Initial and final angiographic occlusions are presented in table 1. Of the 85 patients with follow-up imaging studies, 68 (80\%) underwent catheter angiography, 2 (2.4\%) underwent CT angiography, and 15 (17.6\%) were imaged with MR angiography. At the last follow-up imaging, $90.6 \%$ of all aneurysms, $90 \%$ of unruptured aneurysms, and $93.3 \%$ of ruptured aneurysms had Raymond grade I or II occlusion. Progression to further occlusion (lower Raymond occlusion grade) occurred in 29 aneurysms (34.1\%). Aneurysm recurrence occurred in 11 of 85 aneurysms (12.9\%).

Although men accounted for only $24 \%$ of patients, they accounted for seven of the $11(64 \%)$ recurrences. On logistic regression analysis, recurrence was associated with male gender $(p=0.003)$, age $(p=0.05)$, and aneurysm size $(p=0.005)$. Smoking status, dome:neck ratio, aneurysm location, and use of assistance devices were not significant predictors of recurrence.

Four of the 11 patients with recurrences were re-treated, while the remaining seven were managed conservatively. Therefore, during the study period $4.7 \%$ of patients were re-treated.

\section{Clinical outcome}

Presentation, discharge, and final clinical outcomes based on the mRS are presented in table 2 . Ninety-four per cent of patients $(n=78)$ with unruptured aneurysms had clinical follow-up; of these patients, all but one (98.7\%) had a mRS of 0-2. Sixteen of the 22 patients $(73 \%)$ with SAH had clinical follow-up data; $68.7 \%$ of these patients had a mRS of $0-2$. Both deaths that occurred during the follow-up period were in patients with $\mathrm{SAH}$ and both occurred during the initial hospitalization.

\section{Adverse events}

Delayed AEs, occurring after discharge and during the follow-up period, occurred in $10 \%$ of patients. Six patients experienced procedure-unrelated AEs, while four patients had procedurerelated AEs, of which two were severe and two moderate (table 3). Procedure-related AEs included one thromboembolic complication (embolic infarct related to aneurysm coiling; moderate severity), two access site complications (one severe $\mathrm{AE}$

Table 1 Immediate and last follow-up (FU; before re-treatment) Raymond occlusion grades

\begin{tabular}{|c|c|c|c|c|c|c|}
\hline \multirow[b]{2}{*}{ Raymond occlusion grade } & \multicolumn{2}{|c|}{ All patients, N (\%) } & \multicolumn{2}{|c|}{ Unruptured, N (\%) } & \multicolumn{2}{|c|}{ Ruptured, N (\%) } \\
\hline & Initial & FU & Initial & FU & Initial & FU \\
\hline I (complete occlusion) & 52 & $60(70.6)$ & $38(48.7)$ & $51(72.9)$ & $14(63.6)$ & $9(60)$ \\
\hline II (dog ear) & 17 & $5(5.8)$ & 15 (19.2) & $4(5.7)$ & $2(9.1)$ & $1(6.7)$ \\
\hline II (residual neck) & 16 & $12(14.1)$ & $12(15.4)$ & $8(11.4)$ & $4(18.2)$ & $4(26.7)$ \\
\hline III (residual aneurysm) & 15 & $8(9.4)$ & $13(16.7)$ & $7(10.0)$ & $2(9.1)$ & $1(6.7)$ \\
\hline Total & 100 & 85 & 78 & 70 & 22 & 15 \\
\hline
\end{tabular}


Table 2 Presentation, discharge and last follow-up (FU) modified Rankin scores

\begin{tabular}{|c|c|c|c|c|c|c|c|c|c|}
\hline \multirow[b]{2}{*}{$\begin{array}{l}\text { Modified Rankin } \\
\text { Score }\end{array}$} & \multicolumn{3}{|c|}{ All patients } & \multicolumn{3}{|c|}{ Unruptured } & \multicolumn{3}{|l|}{ Ruptured } \\
\hline & $\begin{array}{l}\text { Initial, } \\
\mathrm{N}(\%)\end{array}$ & $\begin{array}{l}\text { Discharge, } \\
\text { N (\%) }\end{array}$ & $\begin{array}{l}\text { FU, } \\
\mathrm{N}(\%)\end{array}$ & $\begin{array}{l}\text { Initial, } \\
\mathrm{N}(\%)\end{array}$ & $\begin{array}{l}\text { Discharge, } \\
\text { N (\%) }\end{array}$ & $\begin{array}{l}\mathrm{FU}, \\
\mathrm{N}(\%)\end{array}$ & $\begin{array}{l}\text { Initial, } \\
\mathrm{N}(\%)\end{array}$ & $\begin{array}{l}\text { Discharge, } \\
\text { N (\%) }\end{array}$ & $\begin{array}{l}\mathrm{FU}, \\
\mathrm{N}(\%)\end{array}$ \\
\hline 0 & 68 & 65 & 70 (78.7) & $60(76.9)$ & $58(74.4)$ & $64(87.7)$ & $8(36.4)$ & $7(33.3)$ & $6(37.5)$ \\
\hline 1 & 19 & 16 & $10(11.2)$ & $14(17.9)$ & 13 (16.7) & $7(9.6)$ & $5(22.7)$ & $3(14.3)$ & $3(18.8)$ \\
\hline 2 & 5 & 5 & $3(3.4)$ & $3(3.8)$ & $2(2.6)$ & $1(1.4)$ & $2(9.1)$ & $3(14.3)$ & $2(12.5)$ \\
\hline 3 & 2 & 5 & $1(1.1)$ & 0 & $3(3.8)$ & 0 & $2(9.1)$ & $2(9.5)$ & $1(6.3)$ \\
\hline 4 & 6 & 4 & $3(3.4)$ & $1(1.3)$ & $1(1.3)$ & $1(1.4)$ & $5(22.7)$ & $3(14.3)$ & $2(12.5)$ \\
\hline 5 & 0 & 2 & 0 & 0 & $1(1.3)$ & 0 & 0 & $1(4.8)$ & 0 \\
\hline 6 & 0 & 2 & $2(2.2)$ & 0 & 0 & 0 & 0 & $2(9.5)$ & $2(12.5)$ \\
\hline Total & 100 & 99 & 89 & 78 & 78 & 73 & 22 & 21 & 16 \\
\hline
\end{tabular}

associated with groin hematoma and one moderate), and a patient was discovered to have narrowing associated with the catheterized vessel origin on post-procedural imaging, necessitating medical management (severe), but without clinical sequelae. In total, two AEs (one severe and one moderate) were potentially related to the device, thereby providing a $2 \%$ device-related $\mathrm{AE}$ rate.

\section{DISCUSSION}

The final results of the AMERICA trial demonstrate excellent aneurysm occlusion and clinical outcomes using the PGLA-coated Axium MicroFX coils at a mean follow-up of 5.2 months. Of the patients with follow-up angiography, $90.6 \%$ of all aneurysms, 90\% of unruptured aneurysms, and $93.3 \%$ of ruptured aneurysms had Raymond grade I or II occlusion. Progressive occlusion occurred in $34 \%$ of patients. A mRS of 0-2 was obtained in 99\% of those patients treated electively. This prospective study suggests that Axium MicroFX coils have excellent safety and efficacy profiles.

In recent years, a number of innovations in coil coating technology have been developed to encourage aneurysm occlusion, but thus far results have been disappointing. Randomized controlled trials evaluating Cerecyte versus bare platinum coils ${ }^{3}$ and hydrogel-coated coils versus bare platinum showed no significant differences in the primary outcome between advanced coils and traditional bare platinum coils (although recurrence was lower in the hydrogel group in subgroup analyses). ${ }^{4}$ PGLA-coated coils were developed to reduce recurrence

Table 3 Adverse events occurring after discharge

\begin{tabular}{ll}
\hline Event and severity, if applicable & $\%$ Of cases \\
\hline Procedure-related adverse events & 4 \\
Severe & 2 \\
Vertebral artery origin narrowing & 1 \\
Groin hematoma with access site infection & 1 \\
Moderate & 2 \\
Delayed embolic infarct & 1 \\
Access site infection & 1 \\
Mild & 0 \\
Non-procedure-related adverse events & 6 \\
Severe & 1 \\
Moderate & 1 \\
Mild & 4 \\
Total adverse events & 10 \\
\hline
\end{tabular}

through bioactive microfilaments that promote aneurysm thrombosis. Animal studies showed that in comparison with bare platinum coils, PGLA-coated coils increased aneurysmal fibrosis, ${ }^{5}$ leading to their development for human use. Thus far, retrospective and prospective, non-comparative series evaluating the first PGLA coils in humans (Matrix PGLA coils; Boston Scientific, Fremont, CA) have been inconclusive. ${ }^{6-13}$ Progressive aneurysm thrombosis was demonstrated in about $25-30 \%$ of patients $^{6}{ }^{11}$; however, recanalization rates were unacceptably high in several of these studies (up to $54 \%{ }^{10}$ ). The only randomized trial comparing Matrix coils with bare platinum, the Matrix And Platinum Science study, showed no added benefit for Matrix coils over bare platinum, ${ }^{14}$ although this study has yet to be published in a peer-reviewed forum.

The AMERICA series represents the first large, multicenter, prospective study to evaluate the safety and efficacy of PGLA filament containing Axium MicroFX coils. Filaments have been shown to reduce blood flow across the aneurysm neck in addition to the other previously cited benefits of PGLA. We previously demonstrated ${ }^{1}$ that immediate angiographic occlusion in the AMERICA series was comparable to results in other large prospective series. ${ }^{13}$ 15 In addition, periprocedural AEs and mortality were low and similar to historical standards. ${ }^{4}$ 16-20 Similarly, the 3-6 month non-adjudicated follow-up data from AMERICA is comparable, and perhaps better, than coiling studies using non-PGLA technology.

In the HELPS trial recanalization was seen in $24-30 \%$ of patients by 18 months. ${ }^{4}$ In the Cerecyte Coil Trial, composed of both unruptured and ruptured aneurysms, successful outcome at first angiographic follow-up (defined as complete occlusion, stable or improved occlusion compared with initial angiographic results) occurred in only $55 \%$ of patients, with about $6 \%$ of patients re-treated. ${ }^{3}$ In the International Subarachnoid Aneurysm Trial, $76.5 \%$ of patients with SAH treated with coiling had a mRS of $0-2$ at 1 year and complete occlusion or neck remnant was obtained in $92 \%$ of patients at 1 year follow-up angiography. ${ }^{21}$ The more recent Barrow Ruptured Aneurysm Trial demonstrated slightly improved results, with a mRS of $0-2$ in $77 \%$ of patients. By 1 year, $10 \%$ of patients who underwent coiling had been re-trreated. ${ }^{22}$

Although the AMERICA series has a shorter follow-up than any of these studies, the self-reported results suggest at least comparable mid-term occlusion, excellent clinical outcomes, and low adverse event rates. Further core-laboratory adjudicated, prospective or randomized trials are necessary to remove any potential bias and fully evaluate the benefits of PGLA-coated Axium MicroFX coils seen in the AMERICA trial compared with other coil technologies. 
The prospective data obtained from the AMERICA study are limited by the lack of core-laboratory adjudication of clinical and angiographic outcomes, as the individual treatment centers were responsible for determining and self-reporting patient $\mathrm{mRS}$ and Raymond scores. In prior aneurysm occlusion trials, corelaboratory review has indicated lower occlusions rates than with self-reported results from study centers. ${ }^{4} 142023$ This is the most significant limitation of the AMERICA series. In a longterm series evaluating Matrix PGLA coils, mean time to recurrence was 14 months, ${ }^{13}$ which suggests that the 3-6 month follow-up in the AMERICA series might not have provided sufficient time to discover recurrences. In addition, since the subject coil was available only in diameters $\leq 10 \mathrm{~mm}$ at the time of initiating this study, AMERICA intentionally limited inclusion to small and medium aneurysm sizes only. Therefore the data presented herein may not be generalizable to very small or large aneurysms. Lastly, $15 \%$ of patients were lost to imaging follow-up and $11 \%$ did not have clinical follow-up. It is worthwhile noting, however, that the majority of the patients lost to follow-up were treated after acute SAH.

\section{CONCLUSIONS}

In this prospective, multicenter series of 100 aneurysms treated with Axium MicroFX PGLA coils, 3-6 month angiographic occlusion and clinical outcomes were excellent. Delayed procedure-related complications occurred in only four patients. At last follow-up, good outcome (mRS of 0-2) was obtained in all but one $(98.7 \%)$ of the patients with electively treated aneurysms. Aneurysm recurrence and re-treatment were $11 \%$ and $4 \%$, respectively. This study suggests that Axium MicroFX PGLA coils are safe and effective in the treatment of both ruptured and unruptured intracranial aneurysms.

\author{
Author affiliations \\ ${ }^{1}$ Department of Neurosurgery, University of Florida, Gainesville, Florida, USA \\ ${ }^{2}$ Department of Neurosurgery, SUNY Upstate University Hospital, Syracuse, \\ New York, USA \\ ${ }^{3}$ Department of Radiology, West Virginia School of Medicine, Morgantown, West \\ Virginia, USA \\ ${ }^{4}$ Department of Neurosurgery, Thomas Jefferson University, Philadelphia, \\ Pennsylvania, USA \\ ${ }^{5}$ Department of Neurosurgery, University of Southern California, Los Angeles, \\ California, USA \\ ${ }^{6}$ Department of Neurosurgery, University at Buffalo, Buffalo, New York, USA \\ ${ }^{7}$ Department of Neurosurgery, Medical University of South Carolina, Charleston, \\ South Carolina, USA \\ ${ }^{8}$ Department of Neurosurgery, Vanderbilt University, Nashville, Tennessee, USA
}

Contributors All authors contributed to this manuscript by providing patient care, manuscript composition and/or through critical review.

Competing interests JSC serves as a consultant for ev3. PJ serves as a consultant for ev3 and Codman Neurovascular. WJM is supported by a KL2 grant from the National Institute of Health, a Beginning Grant in Aid through the American Heart Association (12BGIA8700001) and the Carol W Harvey Memorial Chair of Research grant through the Brain Aneurysm Foundation. He serves on the Clinical Events Committee/DSMB for the Penumbra Therapy Trial and the core lab for the Stryker FEAT trial. ATR has consulting agreements with Codman Neurovascular and Stryker Neurovascular. AHS has obtained research grants from the National Institutes of Health and University at Buffalo; has financial interests in Hotspur, Intratech Medical, StimSox, and Valor Medical; serves as a consultant to Codman \& Shurtleff, Inc, Concentric Medical, ev3, GuidePoint Global Consulting, Penumbra, and Stryker; participates on the National Steering Committee for the Penumbra 3D Separator Trial; participates on speakers' bureaus for Codman \& Shurtleff, Inc and Genentech; serves on the advisory board for Codman \& Shurtleff; and has received honoraria from Abbott Vascular, American Association of Neurological Surgeons' courses, Genentech, Abbott Vascular and Codman \& Shurtleff, Inc. RDT serves as a consultant for Covidien, Microvention, Codman Neurovascular, Stryker, Penumbra, and Blockade Medical. He has received grant support from Covidien, Codman Neurovascular, and Microvention. JM is a consultant for Lazarus Effect, Pulsar,
Reverse Medical, Edge Therapeutics and has investor interests in Blockade Medical. $\mathrm{KMF}, \mathrm{SB}$, and EMD have no competing interests.

Ethics approval University of Florida IRB.

Provenance and peer review Not commissioned; externally peer reviewed.

\section{REFERENCES}

1 Fargen KM, Blackburn S, Carpenter JS, et al. Early results of the Axium MicroFX for Endovascular Repair of IntraCranial Aneurysm (AMERICA) study: a multicenter prospective observational registry. J Neurointerventional Surg 2014;6:495-9.

2 Raymond J, Guilbert F, Weill A, et al. Long-term angiographic recurrences after selective endovascular treatment of aneurysms with detachable coils. Stroke 2003;34:1398-403.

3 Molyneux AJ, Clarke A, Sneade M, et al. Cerecyte coil trial: angiographic outcomes of a prospective randomized trial comparing endovascular coiling of cerebral aneurysms with either cerecyte or bare platinum coils. Stroke 2012;43:2544-50.

4 White PM, Lewis SC, Gholkar A, et al. Hydrogel-coated coils versus bare platinum coils for the endovascular treatment of intracranial aneurysms (HELPS): a randomised controlled trial. Lancet 2011;377:1655-62.

5 Murayama Y, Vinuela F, Tateshima S, et al. Cellular responses of bioabsorbable polymeric material and Guglielmi detachable coil in experimental aneurysms. Stroke 2002;33:1120-8.

6 Fiorella D, Albuquerque FC, McDougall CG. Durability of aneurysm embolization with matrix detachable coils. Neurosurgery 2006;58:51-9, discussion 51-59.

7 Kang HS, Han MH, Kwon BJ, et al. Short-term outcome of intracranial aneurysms treated with polyglycolic acid/lactide copolymer-coated coils compared to historical controls treated with bare platinum coils: a single-center experience. AJNR Am J Neuroradiol 2005;26:1921-8.

8 Linfante I, Akkawi NM, Perlow A, et al. Polyglycolide/polylactide-coated platinum coils for patients with ruptured and unruptured cerebral aneurysms: a single-center experience. Stroke 2005;36:1948-53.

9 Murayama Y, Vinuela F, Ishii A, et al. Initial clinical experience with matrix detachable coils for the treatment of intracranial aneurysms. J Neurosurg 2006;105:192-9.

10 Niimi Y, Song J, Madrid M, et al. Endosaccular treatment of intracranial aneurysms using matrix coils: early experience and midterm follow-up. Stroke 2006;37:1028-32.

11 Pierot L, Leclerc X, Bonafe A, et al. French Matrix Registry I. Endovascular treatment of intracranial aneurysms with matrix detachable coils: midterm anatomic follow-up from a prospective multicenter registry. AJNR Am J Neuroradiol 2008;29:57-61.

12 Piotin M, Spelle L, Mounayer C, et al. Intracranial aneurysms coiling with matrix: immediate results in 152 patients and midterm anatomic follow-up from 115 patients. Stroke 2009;40:321-3.

13 Piotin M, Pistocchi S, Bartolini B, et al. Intracranial aneurysm coiling with PGLA-coated coils versus bare platinum coils: long-term anatomic follow-up. Neuroradiology 2012;54:345-8.

14 Johnston SC, McDougall CG, Gholkar A. Results of the Matrix and Platinum Science (MAPS) Trial. Colorado Springs, CO: Society of Neurolnterventional Surgery, 2011.

15 Pierot L, Cognard C, Ricolfi F, et al. Immediate anatomic results after the endovascular treatment of ruptured intracranial aneurysms: analysis in the CLARITY series. AJNR Am J Neuroradiol 2010;31:907-11.

16 Naggara ON, White PM, Guilbert F, et al. Endovascular treatment of intracranial unruptured aneurysms: systematic review and meta-analysis of the literature on safety and efficacy. Radiology 2010;256:887-97.

17 Pierot L, Spelle L, Vitry F, et al. Immediate clinical outcome of patients harboring unruptured intracranial aneurysms treated by endovascular approach: results of the ATENA study. Stroke 2008;39:2497-504.

18 Mocco J, Snyder KV, Albuquerque FC, et al. Treatment of intracranial aneurysms with the Enterprise stent: a multicenter registry. J Neurosurgery 2009;110:35-9.

19 Piotin M, Blanc R, Spelle L, et al. Stent-assisted coiling of intracranial aneurysms: clinical and angiographic results in 216 consecutive aneurysms. Stroke 2010;41:110-15.

20 White PM, Lewis SC, Nahser $\mathrm{H}$, et al. HydroCoil Endovascular Aneurysm Occlusion and Packing Study (HELPS trial): procedural safety and operator-assessed efficacy results. AJNR Am J Neuroradiol 2008;29:217-23.

21 Molyneux AJ, Kerr RS, Yu LM, et al. International subarachnoid aneurysm trial (ISAT) of neurosurgical clipping versus endovascular coiling in 2143 patients with ruptured intracranial aneurysms: a randomised comparison of effects on survival, dependency, seizures, rebleeding, subgroups, and aneurysm occlusion. Lancet 2005;366:809-17.

22 McDougall CG, Spetzler RF, Zabramski JM, et al. The Barrow Ruptured Aneurysm Trial. I Neurosurg 2012;116:135-44.

23 Rezek I, Lingineni RK, Sneade M, et al. Differences in the angiographic evaluation of coiled cerebral aneurysms between a core laboratory reader and operators: results of the Cerecyte Coil Trial. AJNR Am J Neuroradiol 2013 Jul 18. [Epub ahead of print]. 